\title{
Thermal integration of different compression-train configurations for coal-fired power plant with carbon capture
}

\author{
Gerardo G. Esquivel-Patiño ${ }^{1}$ Fabricio Nápoles-Rivera' ${ }^{1}$
}

Received: 29 May 2020 / Accepted: 15 January 2021 / Published online: 6 March 2021

(c) The Author(s), under exclusive licence to Springer-Verlag GmbH Germany, part of Springer Nature 2021

\begin{abstract}
Different compression-train configurations in a coal-fired power plant with $\mathrm{CO}_{2}$ capture were thermally integrated to reduce the energetic impact of the capture process and global warming potential for the life cycle of the power plant and the production of the absorbent. The thermal integration was performed using formal optimization techniques, with consideration given to all the available streams for the different compression-train configurations. The different compression-train configurations produced different temperature levels in the process streams and different heat exchanger networks, which included the power plant, compression train, and waste energy recovery technologies, such as organic Rankine cycles. The initial observation was that for the different configurations of the compression trains, the best result in terms of the net power output was 374.26 $\mathrm{MW}_{\mathrm{e}}$, with a reduction of $84.3 \%$ in the global warming potential compared with a power plant without carbon capture. This result was obtained for an eight-stage train with integrally geared centrifugal compressors. Subsequently, with thermal integration, the configuration that included advanced supersonic shockwave compressors exhibited the best conditions for the heat transfer between hot and cold streams, achieving a reduction of $84.65 \%$ in the global warming potential and a net power output of $382.9 \mathrm{MW}_{\mathrm{e}}$.
\end{abstract}

Fabricio Nápoles-Rivera

fnapoles@umich.mx

1 Chemical Engineering Department, Universidad Michoacana de San Nicolás de Hidalgo, 58060 Morelia, Michoacán, Mexico 


\section{Graphic abstract}

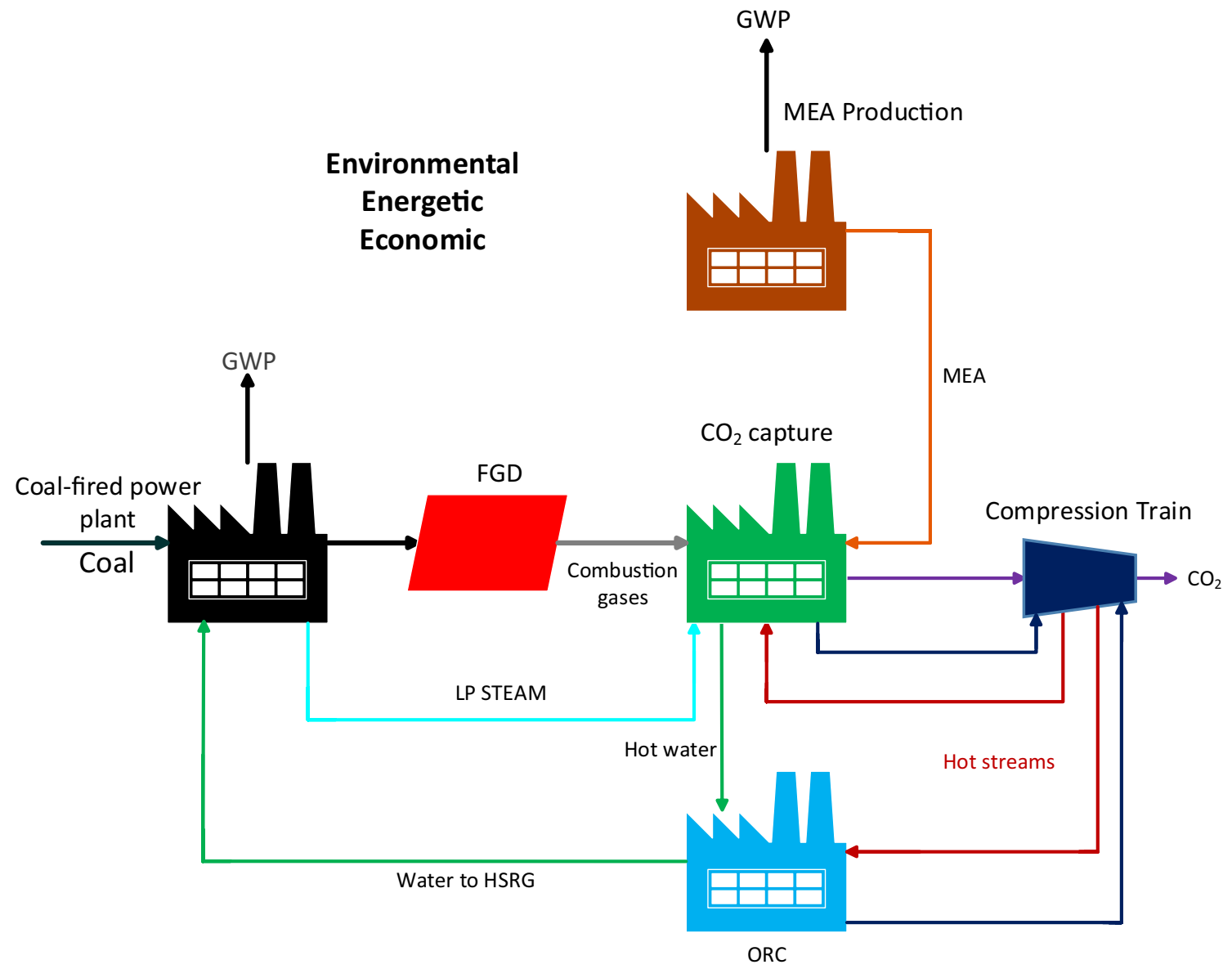

Keywords Coal-fired power plant $\cdot$ Compression train $\cdot$ Thermal integration $\cdot$ Global warming potential

\section{Abbreviations}

COE Cost of electricity

CFPP Coal-fired power plant

CTC Compression-train configuration

DOE/NETL Department of Energy and National Energy Technology Laboratory

GWP Global warming potential

HEN Heat exchanger network

HRSG Heat recovery steam generator

MEA Monoethanolamine

ORC Organic Rankine cycle

PCC Post-combustion carbon capture

\section{Introduction}

Electric power is primarily produced through processes that use fossil fuels. Coal-fired power plants (CFPPs) account for $70 \%$ of the total energy produced by these processes (Hanak et al. 2015), but such power plants have lower heating value efficiencies of approximately $45 \%$ (Li et al. 2019). These processes generate the largest proportion of electrical power and emissions among all the power generation technologies used and even when the CFPP power generation had a diminution of 3\% in 2019 mainly due to the COVID-19 pandemic, coal is still the leader fuel in electricity generation (IEA 2020b). In contrast to that diminution, it was seen an increment in the use of coal in Asia, specifically in China, where the use of coal in power plants has exceeded $50 \%$ of the domestic coal consumption (Wang et al. 2021); also there are more CFPPs under construction or approved to be built (Ouyang et al. 2021), maintaining the $36 \%$ of the total power generation for the CFPPs (IEA 2020a). Around the world, it is expected a $2.6 \%$ rise in global coal demand in 2021 because of an expected recovery in the world economy, driven by higher electricity demand and industrial output. Because of this, countries like the USA and countries in Europe may have their first increases in coal consumption 
in nearly a decade (IEA 2021). Governments and companies around the world have goals to achieve net-zero emissions in the coming decades, more specifically on 2050 (GCCSI 2020); achieving this target could prevent the estimates of $1.5^{\circ} \mathrm{C}$ of global warming between 2030 and 2052 if the growth continues at the current rate (IPCC 2019). It became fundamental to solve the dilemma of how to reconcile the rising demand for energy with the needs of reducing the greenhouse gas emissions and fight the global climate change (Gallagher et al. 2021). That is why, all possible alternatives must be considered to reduce the greenhouse emissions but maintaining an adequate level of power generation to ensure that society's requirements continue to be satisfied. Analyzing carbon capture processes has been an important strategy for achieving these goals (Pacala and Socolow 2004; Desideri and Antonelli 2014; Zhai et al. 2017). However, further research is needed to make the coupling of power plants and carbon capture processes sustainable via methods such as thermal integration, environmental analysis, safety analysis, and optimization (Gingerich and Mauter 2018). In addition, practical alternatives for achieving environmental and power goals have been proposed. Various methods or processes for $\mathrm{CO}_{2}$ capture have been studied to determine the best configuration (Araujo and Medeiros 2017). These include the oxy-combustion process, where the power plant suffers an energy penalty depending on the conventional combustion (Xiong et al. 2011); CaO-based capture, where a large amount of $\mathrm{CO}_{2}$ is captured in a fluidized-bed process (Wang et al. 2011a, 2011b); and processes that use membranes (Gong et al. 2017), ionic liquids (Farahipour and Karunanithi 2014), and microalgae (Sarat-Chandra et al. 2018). Within these methods, the most advanced technology used for $\mathrm{CO}_{2}$ sequestration is a process involving post-combustion capture using chemical absorption. This technology has been investigated with different absorbents, including ammonia (Linnenberg et al. 2012), glycerol as a green absorbent (Flowers et al. 2017), aqueous potassium carbonate (Ghosh et al. 2009), and alcohol amines such as monoethanolamine (MEA), diethanolamine, and triethanolamine (Suleiman et al. 2016; Boucif et al. 2008; Nuchitprasittichai and Cremaschi 2013; Cormos et al. 2018; Wang et al. 2011a, 2011b). Many investigations have been conducted on these types of amines in water solutions and using mixtures of two or more amines. The kinetics and thermodynamics of the amines were studied via simulations and pilot plants (Choi et al. 2009; Zhang et al. 2002; El-Hadri et al. 2017). The main equipment used in the post-combustion process is an absorption tower, in which the $\mathrm{CO}_{2}$ in the combustion gases reacts with an absorbent that is regenerated using a stripping column. The solvent is recovered and recirculated, and the $\mathrm{CO}_{2}$ is separated and subsequently sent to the compression train as a stream with a $\mathrm{CO}_{2}$ concentration of $\geq 90 \%$. Because of the large amount of $\mathrm{CO}_{2}$ generated in a CFPP, the main obstacle to its sustainable capture is the energy expenditure due to the regeneration of the solvent and the power expended in the compression of the $\mathrm{CO}_{2}$ stream (Goto et al. 2013). As previously mentioned, many alternative solvents have been considered, among which MEA is currently the most widely used (Zhang et al. 2017). Despite the potential for reducing $\mathrm{CO}_{2}$ emissions with a carbon capture process, a reduction in the net power output is inevitable with the use of these systems. Several studies have focused on this important limitation.

Parvareh et al. (2014) comprehensively reviewed the integration of solar energy in CFPPs with carbon capture. The main aim of using solar energy is to reduce the energy penalty for the use of carbon capture technologies, which indicates the importance of developing alternative methods to reduce the net power output loss. Luo et al. (2015) examined the heat transfer between the streams of the compression train using the heat recovery steam generator (HRSG) and stripper reboiler of the capture process. Farajollahi and Hossainpour (2017) proposed the use of organic Rankine cycles (ORCs) to exploit the low-grade heat and increase the thermal efficiency of the plant; however, the process streams were matched heuristically. Sanchez del Rio et al. (2017) proposed the integration of a CFPP with post-combustion carbon capture (PCC) using a gas turbine windbox. In this configuration, only a single match between streams was proposed. Oh et al. (2018) proposed a system integration approach for reducing the energy penalty of capture processes in a CFPP and compared their results with those for a pilot-scale plant.

Although previous studies have addressed process integration in CFPPs with carbon capture and compression, none of them involved the use of formal optimization techniques to identify the most suitable matches between process streams. In the best cases, previously reported works used heuristic approaches to determine the optimal matches, and a maximum of three streams were considered in the heat integration.

Methods have been proposed for the formal optimization of a heat exchanger network (HEN). For example, Khalilpour and Abbas (2011) performed a pinch analysis for a 227 MW CFPP. However, it is important to note that pinch analysis is a sequential approach in which the number of heat exchangers and the area are not optimized. Hanak et al. (2014) performed a heat integration and exergy analysis for a CFPP with PCC and a compression train with nine compression stages.

This study analyzed a CFPP with $\mathrm{CO}_{2}$ capture and different compression-train configurations (CTCs). Each of these configurations offered an alternative for thermal integration, which was performed using formal mathematical programming techniques because of the different levels of energy that could be transferred as a result of the changes in the 
number and type of compressors, temperature level in each stage, and pressure ratios. This allowed the energy penalties to be reduced. Thus, all the possible matches between the process streams were considered, which maximized the heat recovery and minimized the number of heat exchangers and their area. Furthermore, the addition of a low-grade heat recovery system such as an ORC was considered to increase the overall thermal efficiency and decrease the energy penalty of the capture process. The steam that was used to regenerate the solvent is considered as one of the streams that can be integrated with the ORC, and this is because the temperature level is not high enough to be integrated with other part of the process. This allowed a heat transfer with the ORC, which is a practical method for using waste energy (Tchanche et al. 2011). The variable levels of capture were subsequently subjected to sensitivity analyses to determine the variation in the most important results based on the decrease or increase in the amount of $\mathrm{CO}_{2}$ (in $\mathrm{kg} / \mathrm{s}$ ) at the end of the capture and compression process.

\section{Materials and methods}

The following simulations were conducted to calculate the parameters:

(a) A $550 \mathrm{MW}$ CFPP,

(b) A PCC MEA-based process,

(c) $\mathrm{A} \mathrm{CO}_{2}$ compression train with different configurations,

Table 1 Cost parameters for SYNHEAT model

\begin{tabular}{ll}
\hline Parameter & Value \\
\hline Heating cost & $5 \$ / 10^{9} \mathrm{~J}$ \\
Cooling cost & $4 \$ / 10^{9} \mathrm{~J}$ \\
Fixed cost of exchangers & $5500 \$ /$ year \\
Fixed cost of heaters & $150 \$ /$ year \\
Fixed cost of coolers & $150 \$ /$ year \\
\hline
\end{tabular}

(d) An ORC with R245FA as the working fluid.

When all the parameters were obtained, the thermal integration was performed using SYNHEAT (Yee and Grossmann 1990). SYNHEAT consists of a mixed-integer nonlinear mathematical model programmed in GAMS that calculates the optimal HEN by minimizing the cost, which includes the investment cost, annual cost, and utility cost. Thereby, the available hot and cold streams of a process were matched, and the heating and cooling requirements were satisfied. Table 1 presents the main economic parameters used in the model, which were obtained from the study of Gonzalez-Bravo et al. (2015). This study principally modified the numbers of hot and cold streams and their operational conditions according to each compression-train configuration (CTC) to obtain the optimal HEN for each scenario studied.

Finally, the global warming potential (GWP) and power output were calculated for the base cases with a fixed amount of $\mathrm{CO}_{2}$ capture $(90 \%)$. Sensitivity analyses were then performed with varying amounts of $\mathrm{CO}_{2}$ capture using the model analysis tools of Aspen Plus ${ }^{\mathrm{TM}}$.

\section{Aspen Plus ${ }^{\mathrm{Tm}}$ simulations}

The simulation depicted in Fig. 1 was conducted for a CFPP with a capacity of $550 \mathrm{MW}$ using the parameters used by Oh et al. (2018) and those used in case 11 of a supercritical power plant in a report published by the U.S. Department of Energy and National Energy Technology Laboratory (DOE/ NETL) (2013). Thus, all the necessary data for the thermal integration, such as the stream temperatures and heat capacities, were obtained for the capture process, in which the flow of combustion gases from the thermoelectric plant was fed to the absorber with a $35 \mathrm{wt} \%$ MEA as absorbent, using the models and parameters employed by Zhang et al. (2009) for the capture process simulation. Separate simulations of steam turbines with three levels of pressure were carried out with the parameters of the DOE/NETL report, HP turbine $\left(24.23 \mathrm{MPa} / 593{ }^{\circ} \mathrm{C}\right)$, IP turbine $\left(4.52 \mathrm{MPa} / 593{ }^{\circ} \mathrm{C}\right)$,

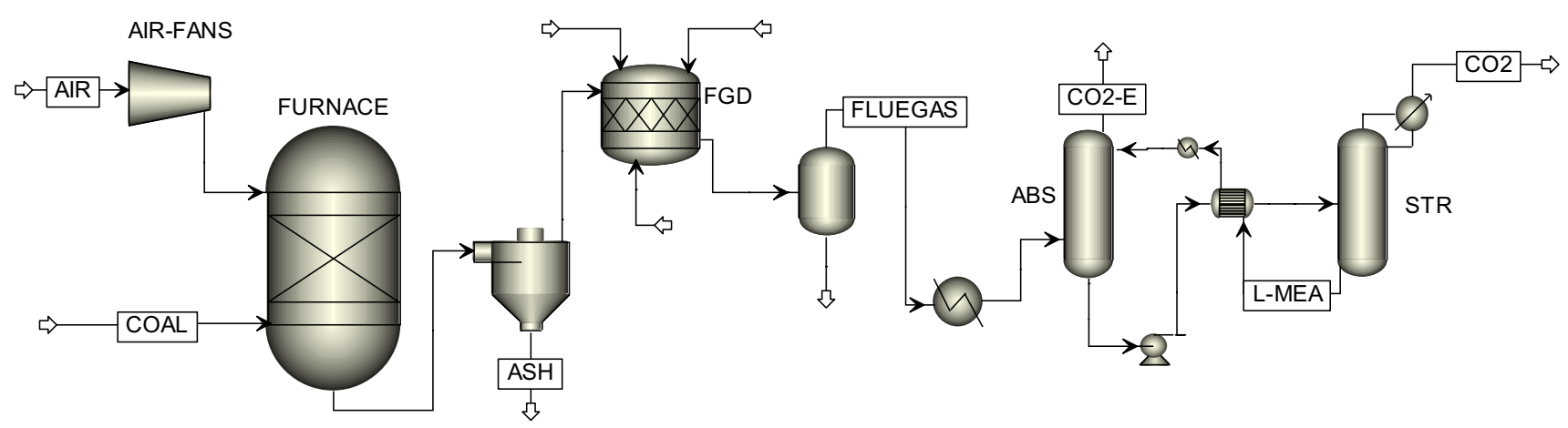

Fig. 1 Simulation of CFPP with $\mathrm{CO}_{2}$ capture process 
and condenser with an outlet temperature of $39^{\circ} \mathrm{C}$ (Fig. 2), where the steam extracted to regenerate the absorbent was extracted from the IP/LP crossover point of the steam cycle. A simulation was also performed to obtain the parameters for calculating the net power and GWP, such as the heat of the reboiler, required power in the compression train, extracted steam, output power of the steam turbines, power of the output ORC, contribution of GWP in the production of MEA, contribution of GWP in the stage of the CFP, and flow of captured $\mathrm{CO}_{2}$. Table 2 presents the main parameters for the simulation of the CFPP, PCC process, and ORC.

Figure 3 shows a simulation of the capture process and CTCs in which a stream duplicator was used to maintain the same stream from the stripper to the compressors. The
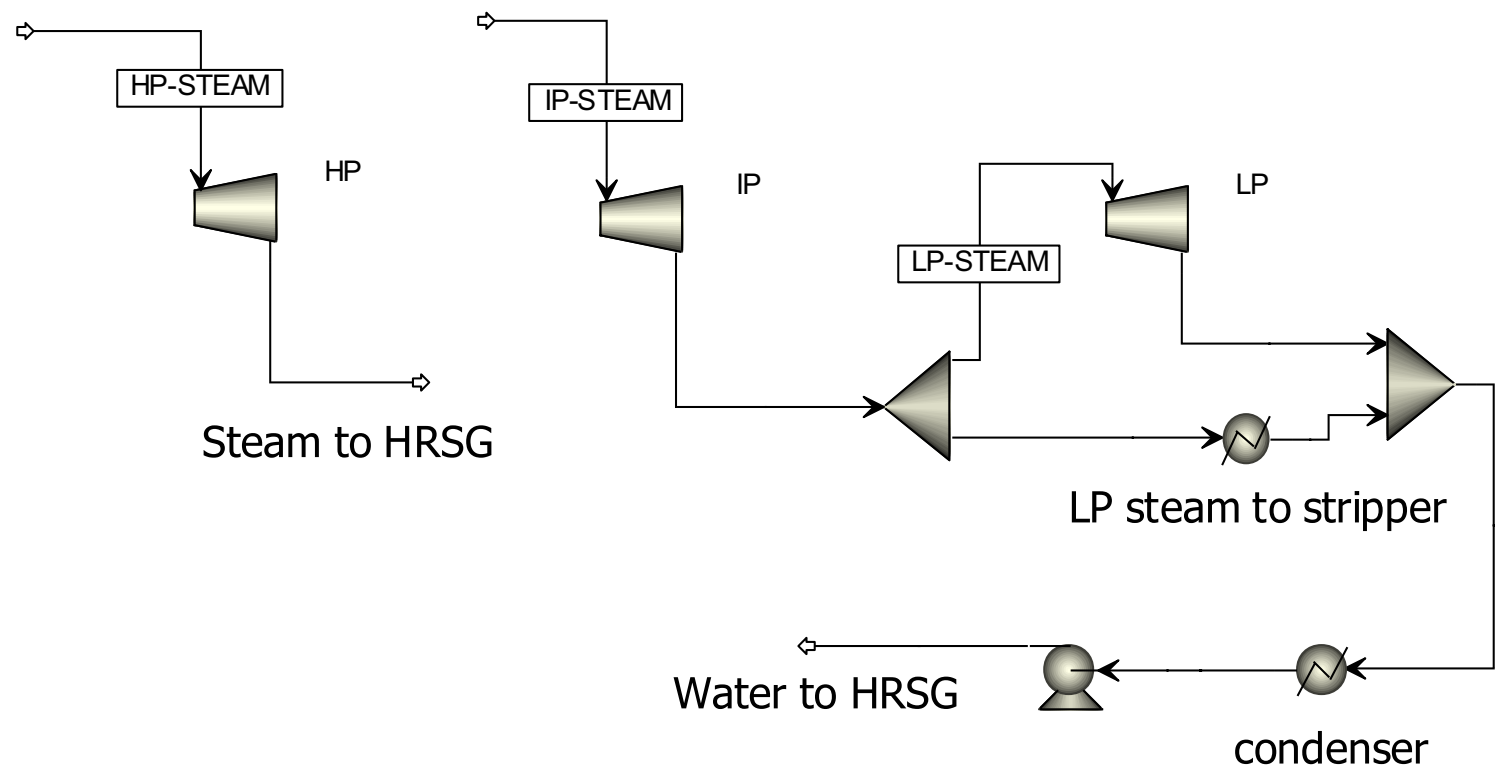

Fig. 2 Simulation of steam turbines

Table 2 Main parameters of CFPP, PCC, and ORC process simulation

\begin{tabular}{|c|c|c|}
\hline Parameter & Value & References \\
\hline Coal flow rate $(\mathrm{kg} / \mathrm{h})$ & 185,759 & Oh et al. (2018) \\
\hline Coal conditions $\left({ }^{\circ} \mathrm{C} / \mathrm{bar}\right)$ & $15 / 1.01325$ & DOE/NETL (2013) \\
\hline Air flow rate $(\mathrm{kg} / \mathrm{h})$ & $1,748,073$ & DOE/NETL (2013) \\
\hline Lean amine inlet conditions $\left(\mathrm{bar} /{ }^{\circ} \mathrm{C}\right)$ & $5.0033 / 34.95$ & Zhang et al. (2009) \\
\hline Absorber pressure (bar/stages) & $1.5 / 20$ & Zhang et al. (2009) \\
\hline Rich amine inlet conditions $\left(\mathrm{bar} /{ }^{\circ} \mathrm{C}\right)$ & $9.8133 / 105$ & Zhang et al. (2009) \\
\hline Stripper pressure (bar/stages) & $2.4 / 20$ & Zhang et al. (2009) \\
\hline Stripper reboiler duty (MW) & 431.94 & Zhang et al. (2009) \\
\hline R245FA flow (kg/s) & 13.4 & Filiz-Ozdil-Tumen and Ridvan-Segmen (2016) \\
\hline Pump discharge pressure (bar) & 8 & Filiz-Ozdil-Tumen and Ridvan-Segmen (2016) \\
\hline Hot stream outlet temperature $\left({ }^{\circ} \mathrm{C}\right)$ & 48 & Filiz-Ozdil-Tumen and Ridvan-Segmen (2016) \\
\hline Evaporator outlet temperature $\left({ }^{\circ} \mathrm{C}\right)$ & 90 & Filiz-Ozdil-Tumen and Ridvan-Segmen (2016) \\
\hline ORC turbine discharge pressure (bar) & 2.805 & Filiz-Ozdil-Tumen and Ridvan-Segmen (2016) \\
\hline ORC condenser outlet temperature $\left({ }^{\circ} \mathrm{C}\right)$ & 30 & Filiz-Ozdil-Tumen and Ridvan-Segmen (2016) \\
\hline SSWC CTC stage pressures (bar) & $15.57 / 153$ & Witkowski and Majkut (2012) \\
\hline CC-4 CTC stage pressures (bar) & $4.9 / 16.5 / 50 / 153$ & Witkowski and Majkut (2012) \\
\hline CC-6 CTC stage pressures (bar) & $4.3 / 9.6 / 21.5 / 44.9 / 82.7 / 153$ & Witkowski and Majkut (2012) \\
\hline CC-8 CTC stage pressures (bar) & $\begin{array}{l}2.775 / 4.924 / 8.734 / 15.55 / 27.45 / 48.64 / 8 \\
\quad 6.27 / 153\end{array}$ & Witkowski and Majkut (2012) \\
\hline Intercoolers gas outlet temperature $\left({ }^{\circ} \mathrm{C}\right)$ & 30 & Witkowski and Majkut (2012) \\
\hline
\end{tabular}




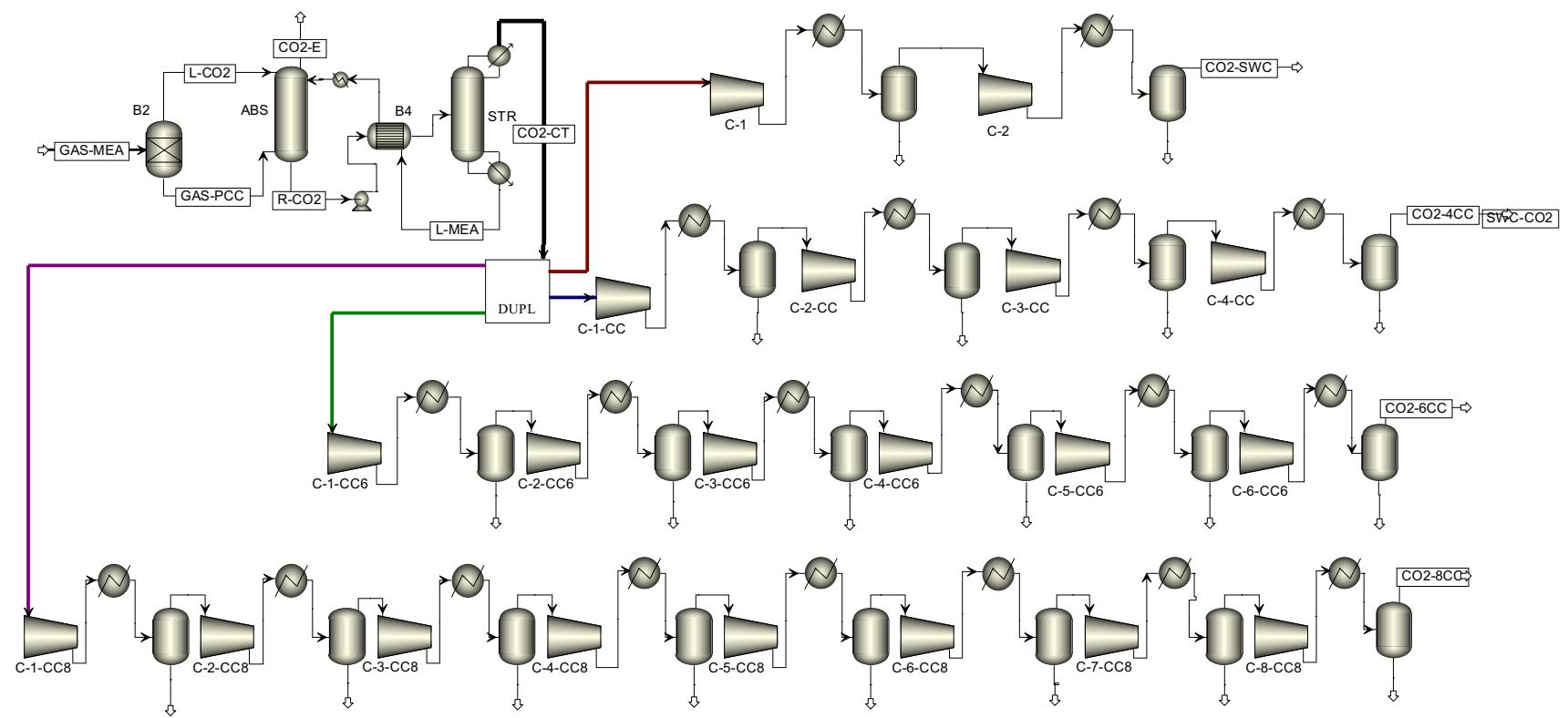

Fig. 3 Simulation of $\mathrm{CO}_{2}$ capture process with different CTCs

device before absorber B2 is a splitter that ensures that the relationships between the lean solvent and the flue gas remain constant for all the points considered in the analysis. The simulation parameters for all the compression configurations were obtained from the study of Witkowski and Majkut (2012). The first CTC in Fig. 3 corresponds to the advanced supersonic shockwave compressors (SSWCs), and the other three correspond to centrifugal compressors, with the number of compression stages varying from 4 to 8 .

A comparison was made of the parameters of case 11 in the DOE/NETL report for the stream of the combustion gases (Stream 18 in the DOE/NETL report). The lean amine stream flux was estimated using the parameters of Oh's studies on the lean amine ratio $\left(\mathrm{CO}_{2} \mathrm{~mol} / \mathrm{MEA} \mathrm{mol}\right)$ and a $\mathrm{CO}_{2}$ recovery of $90 \%$, obtaining a lean amine ratio of 0.26 with a total flux of $1681.58 \mathrm{~kg} / \mathrm{s}$, and the rich amine ratio resulting of the simulation is 0.43 . This study analyzed the impact of coupling the carbon capture to the CFPP with the same feed of coal as in case 11 .

The most important results of the base simulation in this study were compared for a base case scenario. The output power of $550.06 \mathrm{MW}$, specific reboiler heat of 3.43 $\mathrm{GJ} / \mathrm{tCO}_{2}$, the reboiler temperature of $108.2{ }^{\circ} \mathrm{C}$ and the liquid-gas $(\mathrm{kg} / \mathrm{kg})$ ratio of 2.86 were close to the values of $550 \mathrm{MW}, 3.57 \mathrm{GJ} / \mathrm{tCO}_{2}, 108{ }^{\circ} \mathrm{C}$ and 3.08 obtained by $\mathrm{Oh}$ et al., respectively. Additionally, the power output of a base simulation of the ORC (0.2602 MW) was compared with that reported by Filiz-Ozdil-Tumen and Ridvan-Segmen (2016) (0.2604 MW).

The results for the CFPP as a base case scenario for comparison were also obtained from the simulation. Initially, the GWP for a CFPP without capture was calculated. The emission was $802.15 \mathrm{e}-\mathrm{CO}_{2} \mathrm{~g} / \mathrm{kWh}$, and a gross power value of 580.46 MW was obtained from a simulation of the steam turbines. The net power output was calculated using this information and the data on the consumption of energy in the auxiliary services of the plant found in the DOE/NTEL report.

\section{Thermal integration}

Figure 4 shows the thermal integration scheme, which considered the possibility of a match between the hot streams of the compression-train section and the cold streams in the amine regeneration process, as well as the streams of the ORC. The hot streams had different temperature levels with different compression configurations. The possibility of using the stream of hot water at the output of the capture process (Fig. 3) in the ORC to generate power was also considered. This stream was generated by the condensation of a stream of low-pressure (LP) steam used in the stripper to regenerate the amine. It was subsequently used as hot liquid water that still had a temperature of approximately $151{ }^{\circ} \mathrm{C}$, because it had a considerable mass flow in the scenario without thermal integration $(179.36 \mathrm{~kg} / \mathrm{s})$. Its flux decreased according to the thermal integration of each scenario; thus, the amount of steam used in the stripper reboiler was reduced. The matching between the hot water stream and the ORC was fixed for each scenario, but as the hot water flow differed among the cases studied, the ORC produced different levels of electrical power for the 


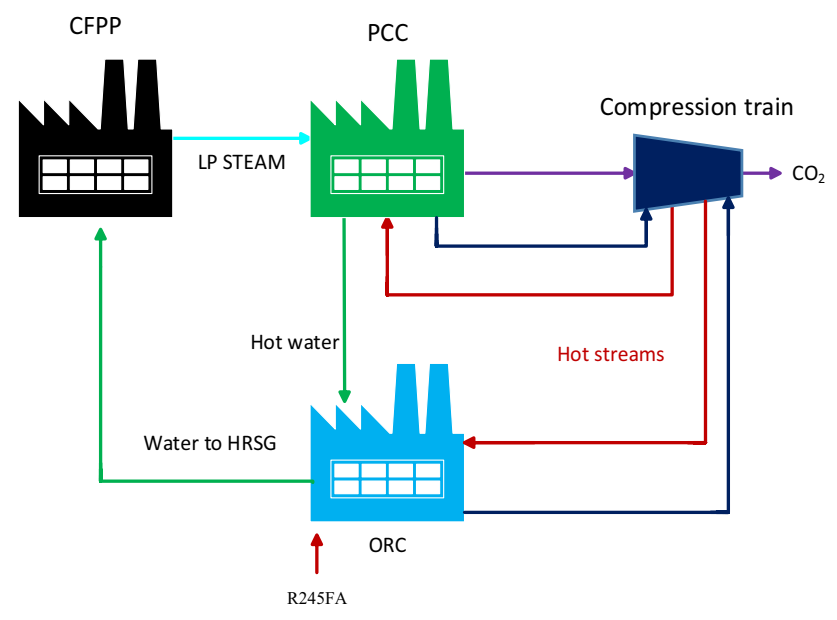

Fig. 4 Thermal integration scheme

different cases. These power values were then added to the results of the thermal integration conducted in SYNHEAT.

Table 3 presents details of the hot and cold streams considered for all the thermal integrations for each CTC. The cold streams were the same for each scenario studied. C1 was the stream at the inlet of the stripper reboiler, and its temperature conditions were obtained from the Aspen Plus simulations. C2 was the stream that was fed into the ORC evaporator, and the hot streams were the compression-train streams of each configuration scenario.
The heat capacity flow rate of each hot and cold stream was calculated from the simulation results and for the scenario of ORC evaporator stream $\mathrm{C} 2$, whose heat capacity flow rate was initially calculated for a $0.2602 \mathrm{MW}$ ORC. For each scenario studied, the value of the heat capacity flow rate was incremented in the thermal integration in SYNHEAT until the stream began to consume hot utility instead of using the compression-train hot streams. Thus, the maximum duty transferred to stream $\mathrm{C} 1$ in the scenario analyzed without an ORC was maintained.

\section{Calculating GWP and net power output by varying capture level percentages}

The scheme for analyzing the GWP and net power output is shown in Fig. 5. The main objective was to observe the variation in the aforementioned parameters according to the decrease in the capture level, which directly affected the amount of greenhouse gases emitted, amount of absorbent fed, amount of LP steam extracted for the desorption, amount of heat in the reboiler of the stripper, GWP values in the stages considered, global GWP, and production of energy. The simulation results were used to calculate the net energy generated from the process and the GWP for each point in the sensitivity analysis for each CTC. When calculating the GWP, the emissions due to the production of the absorbent and the emissions in the CFPP were considered. The net power was calculated using Eq. (1), which shows the gross power generated in the steam turbines and ORC

Table 3 Hot and cold streams for each scenario studied

\begin{tabular}{|c|c|c|c|c|c|c|}
\hline Study scenario & Hot and cold str & emperatures ( & /out) & & & \\
\hline $\mathrm{CFPP}+\mathrm{PCC}+\mathrm{SSWC}$ & H1 (254/38) & H2 (273/38) & C1 (108/118.7) & C2 (48/90) & & \\
\hline $\mathrm{CFPP}+\mathrm{PCC}+\mathrm{CC}-4$ & H1 (136/38) & H2 (155/38) & H3 (151/38) & H4 (154/38) & C1 (108/118.7) & C2 (48/90) \\
\hline $\mathrm{CFPP}+\mathrm{PCC}+\mathrm{CC}-6$ & $\begin{array}{l}\text { H1 }(121 / 38) \\
\text { C1 }(108 / 118.7)\end{array}$ & $\begin{array}{l}\text { H2 }(110 / 38) \\
\text { C2 }(48 / 90)\end{array}$ & H3 $(113 / 38)$ & H4 (110/38) & H5 $(98 / 38)$ & H6 (80/38) \\
\hline $\mathrm{CFPP}+\mathrm{PCC}+\mathrm{CC}-8$ & $\begin{array}{l}\text { H1 }(83 / 38) \\
\text { H7 }(95 / 38)\end{array}$ & $\begin{array}{l}\text { H2 }(89 / 38) \\
\text { H8 }(71 / 38)\end{array}$ & $\begin{array}{l}\text { H3 }(91 / 38) \\
\text { C1 }(108 / 118.7)\end{array}$ & $\begin{array}{l}\text { H4 }(92 / 38) \\
\text { C2 }(48 / 90)\end{array}$ & H5 $(93 / 38)$ & H6 $(95 / 38)$ \\
\hline
\end{tabular}
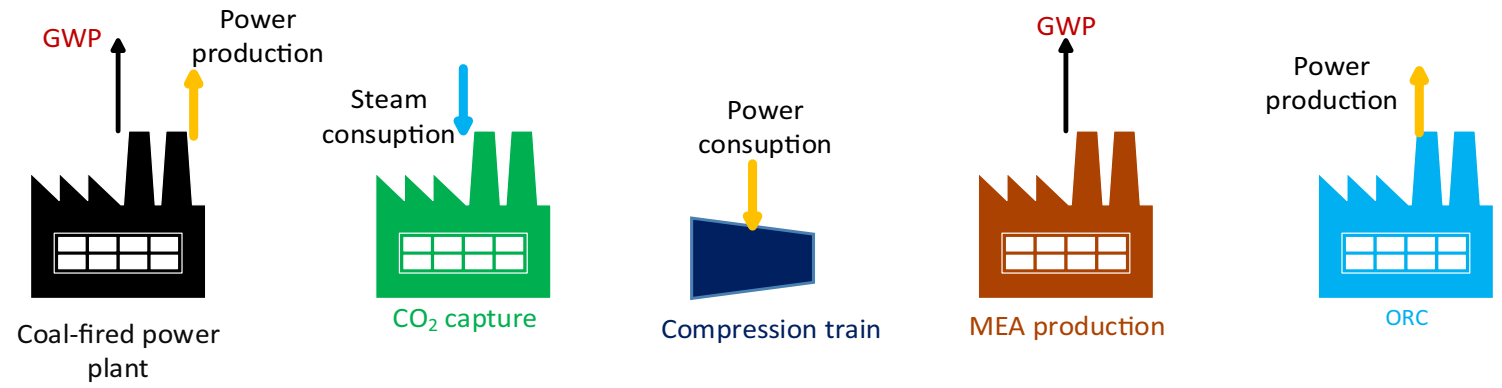

Fig. 5 Scheme of GWP and net power output estimation 
minus the power values for the auxiliary energy consumption (Paux), which is taken from the DOE/NETL and equal to $30.41 \mathrm{MWe}$; the energy consumption in the compression train (Pcomp), which depends on each study case; and the energy used in the capture process (Pcap), which depends on the LP steam extracted from the HRSG to the PCC. The CFPP efficiency was calculated using Eq. (2), where $\mathrm{HVV}$ was taken from the report by $\mathrm{Oh}$ et al. and is equal to $27,113 \mathrm{~kJ} / \mathrm{Kg}$ and $F_{\text {coal }}$ is the flow rate of coal to the CFPP. The values in equivalent grams of $\mathrm{CO}_{2}$ from the IPCC were used as the parameters, and data from the ECOINVENT database (2019) were used for the absorber emissions. The points considered in the analysis were for capture levels of $90 \%, 70 \%, 50 \%$, and $25 \%$, and thermal integration was conducted for the SSWC configuration to obtain the GWP and net power output for each point.

$n P=$ Gross power $-($ Paux + Pcap + Pcompr $)$

$n=\frac{n P}{\mathrm{HHV} * F_{\text {coal }}}$.

To obtain another decision criterion for the CTCs, an economic analysis was performed in Aspen Plus, in which the equipment cost, capital cost, and annual operation and maintenance cost were calculated in separate simulations for each CTC. Using these data, the cost of electricity (COE) was calculated for each CTC considered. The COEs of the standalone CFPP were identical for all the cases and were calculated using Eq. (3) in the DOE/NETL report.

$\mathrm{COE}=\frac{\mathrm{CCF} * \mathrm{TOC}+\mathrm{OCFIX}+\mathrm{OCVAR}}{\mathrm{CF} * \mathrm{MWH}}$.

Here, COE represents the revenue produced by the generator $(\$ / \mathrm{MWh}) ; \mathrm{CCF}=0.124$ represents the capital charge factor; TOC represents the total overnight capital (in baseyear dollars); OCFIX represents the sum of all the fixed annual operating costs (in base-year dollars); OCVAR represents the sum of all the variable annual operating costs, including the fuel at a capacity factor of $100 \%$ (in base-year dollars); CF represents the plant capacity factor, which was assumed to be constant ( $85 \%$ ) over the operational period; and MWH represents the annual net megawatt-hours of power generated at a $100 \%$ capacity factor.

\section{Results and discussion}

Table 4 and Fig. 6 present the results of the simulations for a CFPP with carbon capture for all the CTCs, for a capture level of $90 \% \mathrm{CO}_{2}$ recovery. The net power output of each scenario differed from that of the CFFP without capture. The first scenario corresponded to the advanced SSWCs, and the subsequent scenarios corresponded to centrifugal compressors (CC-4, 6, and 8).

The net power output decreased by $31-34 \%$ for each scenario compared with the CFPP without carbon capture and thermal integration, and the GWP decreased by $83-84 \%$ for each scenario. The best results for the net power ( 374.26 $\mathrm{MW}_{\mathrm{e}}$ ) and GWP (a decrease of 84.3\%) were obtained for the eight-stage integrally geared centrifugal compressors (CC-8) compared with the power plant without carbon capture. This is because the CC-8 configuration had a lower energy consumption. The SSWC configuration had a lower net power output because of the energy consumed to compress the $\mathrm{CO}_{2}$ to make its GWP greater than that of the CC configurations. Figures 7, 8, and 9 show the heat transfer networks obtained for each configuration. Different matches and results were obtained.

\section{Case 1: SSWC configuration}

Figure 6 shows the HEN of case 1, in which there were four matches between the hot and cold streams. The main conclusions were as follows:

- Steams H1 and H2 were coupled with $\mathrm{C} 1$, and $41.578 \mathrm{MW}$ of power was transferred; this reduced the LP steam to be extracted to satisfy the remaining 390.4 MW of heat required for the stripper reboiler operation.

- Streams H1 and H2 were used to evaporate the working fluid in the ORC, which produced 1.526 MW.

Table 4 Results of simulations

\begin{tabular}{lllccc}
\hline Result & CFPP & CFPP+PCC+SSWC & CFPP+PCC+CC-4 & CFPP+ PCC+CC-6 & CFPP+ PCC+CC-8 \\
\hline Stripper reboiler duty (MW) & - & 431.94 & 431.94 & 431.94 & 431.94 \\
Power consumed by compressors (MW) & - & 46.12 & 42.18 & 38.45 & 37.12 \\
Net power output (MW $)$ & 550 & 365.26 & 369.2 & 372.93 & 374.26 \\
$\mathrm{CO}_{2}$ captured $(\mathrm{kg} / \mathrm{s})$ & 110.3 & 110.3 & 110.3 & 110.3 & 110.3 \\
GWP $\left(\mathrm{e}-\mathrm{CO}_{2}\right.$ g/kWh) & 802.15 & 129.07 & 127.7 & 126.42 & 125.97 \\
CFPP efficiency (HHV) & $39.3 \%$ & $26.1 \%$ & $26.38 \%$ & $26.64 \%$ & $26.74 \%$ \\
\hline
\end{tabular}




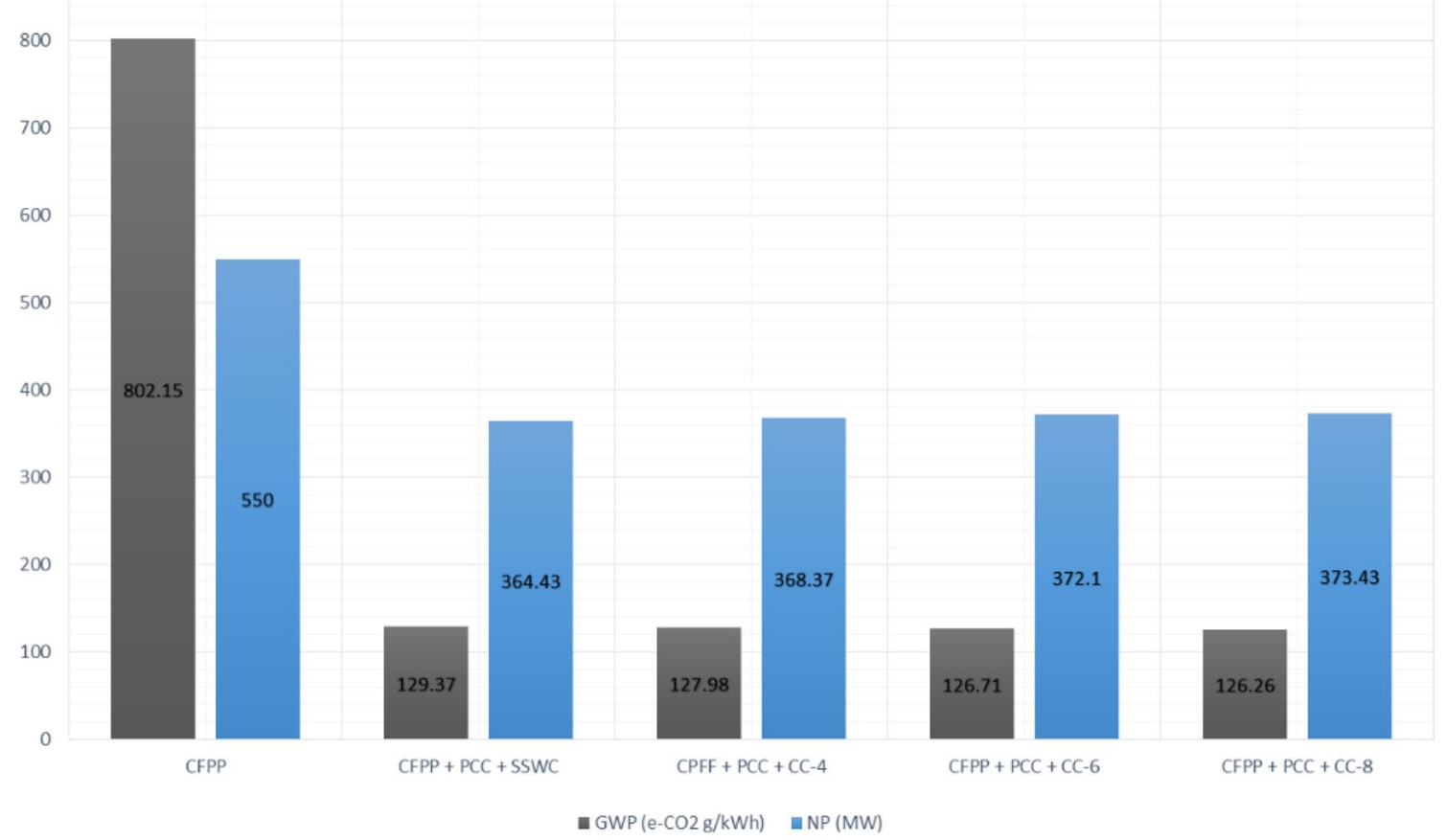

Fig. 6 GWP and net power output results

Fig. 7 HEN for SSWC configuration

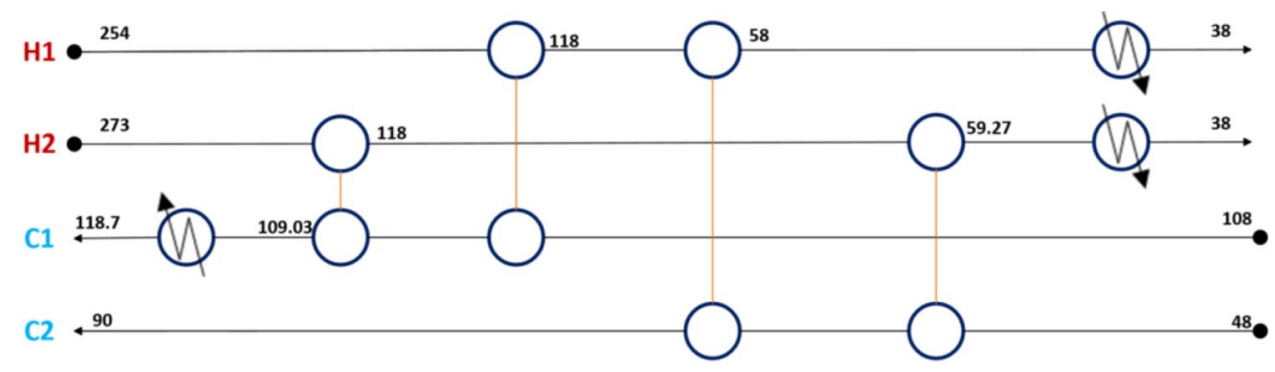

Fig. 8 HEN for CC-4 configuration

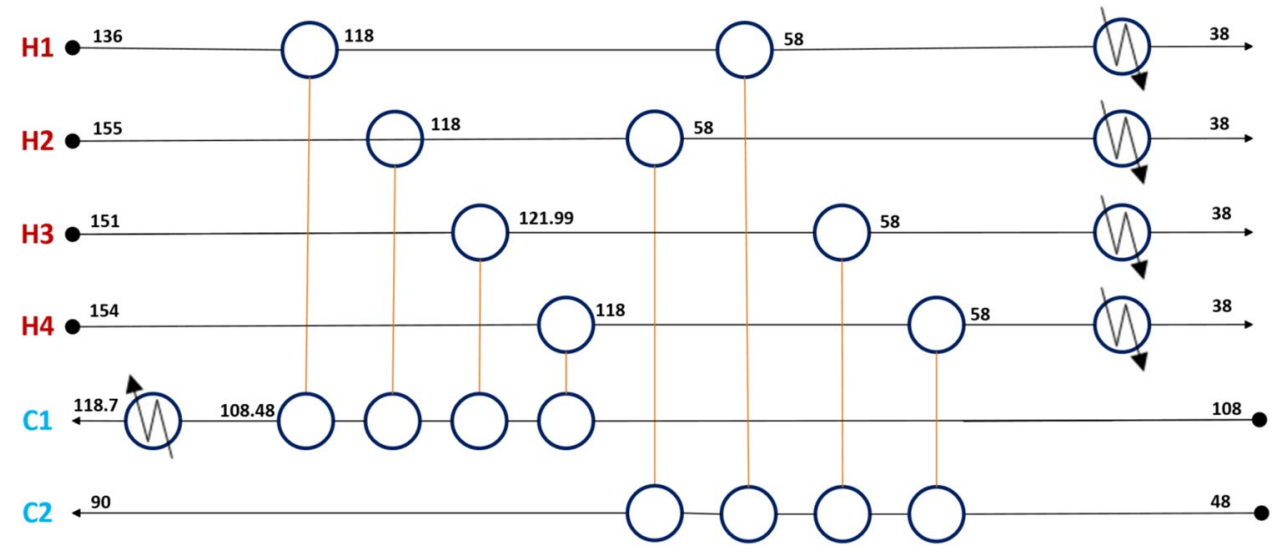

- The required consumption of the cold utility to cool the streams of the compression train without thermal integration was 64.249 MW; with the obtained HEN, it decreased to $21.184 \mathrm{MW}$.

\section{Case 2: CC-4 configuration}

Figure 7 shows the HEN obtained for case 2. There were eight matches between the hot and cold streams. The main results were as follows: 
Fig. 9 HEN for CC-6 configuration

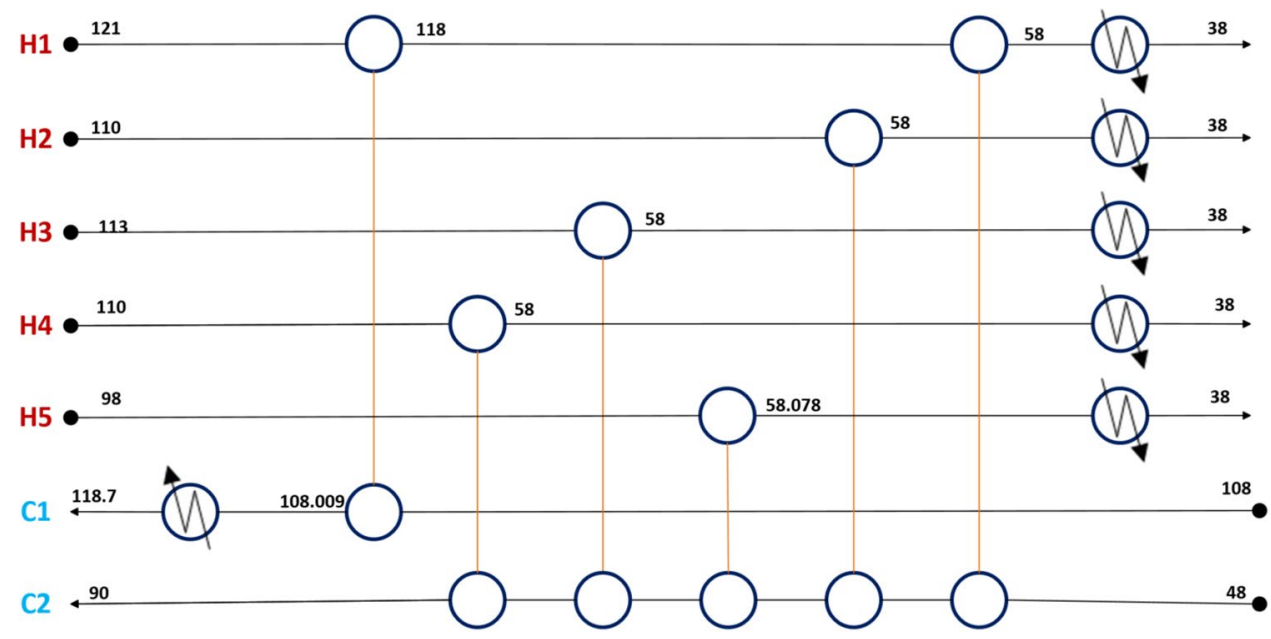

- $\mathrm{H} 1, \mathrm{H} 2, \mathrm{H} 3$, and $\mathrm{H} 4$ were coupled with $\mathrm{C} 1$, and the heat transfer between them was 19.409 MW; this reduced the amount of LP steam that needed to be extracted to provide the remaining $412.53 \mathrm{MW}$ of heat required for the stripper reboiler operation.

- The heat in streams H1, H2, H3, and H4 was transferred to $\mathrm{C} 2$ to evaporate the working fluid in the ORC, which produced 3.43 MW.

- The required consumption of the cold utility to cool the streams of the compression train without thermal integration was $69.635 \mathrm{MW}$; with the HEN, it decreased to $46.852 \mathrm{MW}$.

\section{Case 3: CC-6 configuration}

Figure 9 shows the HEN obtained for case 3; there were six matches between the hot and cold streams, and the observations were as follows:

- Stream H6 was not used in the HEN because of its low temperature.

- H1 was coupled with $\mathrm{C} 1$, and $0.357 \mathrm{MW}$ of power was transferred; this reduced the amount of LP steam that needed to be extracted for the stripper reboiler, whose heat requirement became $431.58 \mathrm{MW}$.

- Streams H1, H2, H3, H4, and H5 were used to evaporate the working fluid in the ORC, which produced $3.243 \mathrm{MW}$.

- The consumption of the cold utility decreased from 64.791 to $61.269 \mathrm{MW}$ with thermal integration.

\section{Case 4: CC-8 configuration}

None of the hot streams were used to transfer heat to the $\mathrm{C} 1$ or $\mathrm{C} 2$ streams in case 4 . This was because all the streams had a temperature below $100{ }^{\circ} \mathrm{C}$; thus, the stripper reboiler duty and consumption of cold utility to cool the streams of the compression train maintained the same value. A match with stream H6 was observed only when the heat capacity flow rate of the $\mathrm{C} 2$ stream in the thermal integration decreased. However, it required an additional consumption of hot utility in the ORC, which contributed to the cold utility utilized to condense the working fluid and had an energy production of only 0.1 MW (in the ORC). This had a negligible impact on the global process. The only match in this scenario was between the hot water streams at the output of the stripper reboiler and the ORC that could generate $4.67 \mathrm{MW}_{\mathrm{e}}$, which contributed to the global energy production of the CFPP.

The results for the net power output and GWP are presented in Table 5 for the scenario with thermal integration, in which the GWP initially decreased because the net power output of each scenario increased as a result of the matches between the hot and cold streams calculated for each scenario. In contrast to the case without thermal integration, in which the CC- 8 configuration exhibited the best energetic and environmental results, the SSWC configuration with thermal integration produced a higher net power output of $382.9 \mathrm{MW}_{\mathrm{e}}$ and a lower GWP (by 84.65\%) than the scenario without carbon capture; it also had a lower consumption of cold utility in the compression-train intercooler. This was because the hot streams attained temperatures higher than $200{ }^{\circ} \mathrm{C}$, which allowed for thermal integration with the stripper reboiler and ORC, yielding better results compared with those of the other configurations, whose streams had temperatures below $150{ }^{\circ} \mathrm{C}$. Figure 10 shows a flowchart of a CFPP with carbon capture and an SSWC configuration with initial thermal integration between compression-train hot streams $\mathrm{H} 1$ and $\mathrm{H} 2$, and the stripper reboiler and streams of the working fluid used in the ORC.

Based on the analysis of the variation in the capture level, the GWP and net power were obtained for capture levels ranging from 0 to $90 \%$ for each CTC. The variation in the GWP against the net power output is shown in Fig. 11 for the SSWC configuration, because it was the CTC with thermal 
Table 5 Results of thermal integration

\begin{tabular}{|c|c|c|c|c|c|}
\hline Result & CFPP & $\mathrm{CFPP}+\mathrm{PCC}+\mathrm{SSWC}$ & $\mathrm{CFPP}+\mathrm{PCC}+\mathrm{CC}-4$ & $\mathrm{CFPP}+\mathrm{PCC}+\mathrm{CC}-6$ & $\mathrm{CFPP}+\mathrm{PCC}+\mathrm{CC}-8$ \\
\hline Stripper reboiler duty (MW) & - & 390.4 & 412.53 & 431.58 & 431.94 \\
\hline LP steam extracted $(\mathrm{kg} / \mathrm{s})$ & - & 162.1 & 171.3 & 179.21 & 179.36 \\
\hline $\begin{array}{l}\text { Power consumed by the com- } \\
\text { pressors (MW) }\end{array}$ & - & 46.12 & 42.18 & 38.45 & 37.12 \\
\hline ORC power output $\left(\mathrm{MW}_{\mathrm{e}}\right)$ & - & 5.8 & 7.9 & 7.91 & 4.67 \\
\hline Net power output $\left(\mathrm{MW}_{\mathrm{e}}\right)$ & 550 & 382.9 & 382.64 & 380.9 & 379.61 \\
\hline $\mathrm{CO}_{2}$ captured $(\mathrm{kg} / \mathrm{s})$ & 110.3 & 110.3 & 110.3 & 110.3 & 110.3 \\
\hline $\mathrm{GWP}\left(\mathrm{e}-\mathrm{CO}_{2} \mathrm{~g} / \mathrm{kWh}\right)$ & 802.15 & 123.12 & 123.21 & 123.35 & 124.42 \\
\hline CFPP efficiency (HHV) & $39.3 \%$ & $27.4 \%$ & $27.34 \%$ & $27.22 \%$ & $27.12 \%$ \\
\hline
\end{tabular}

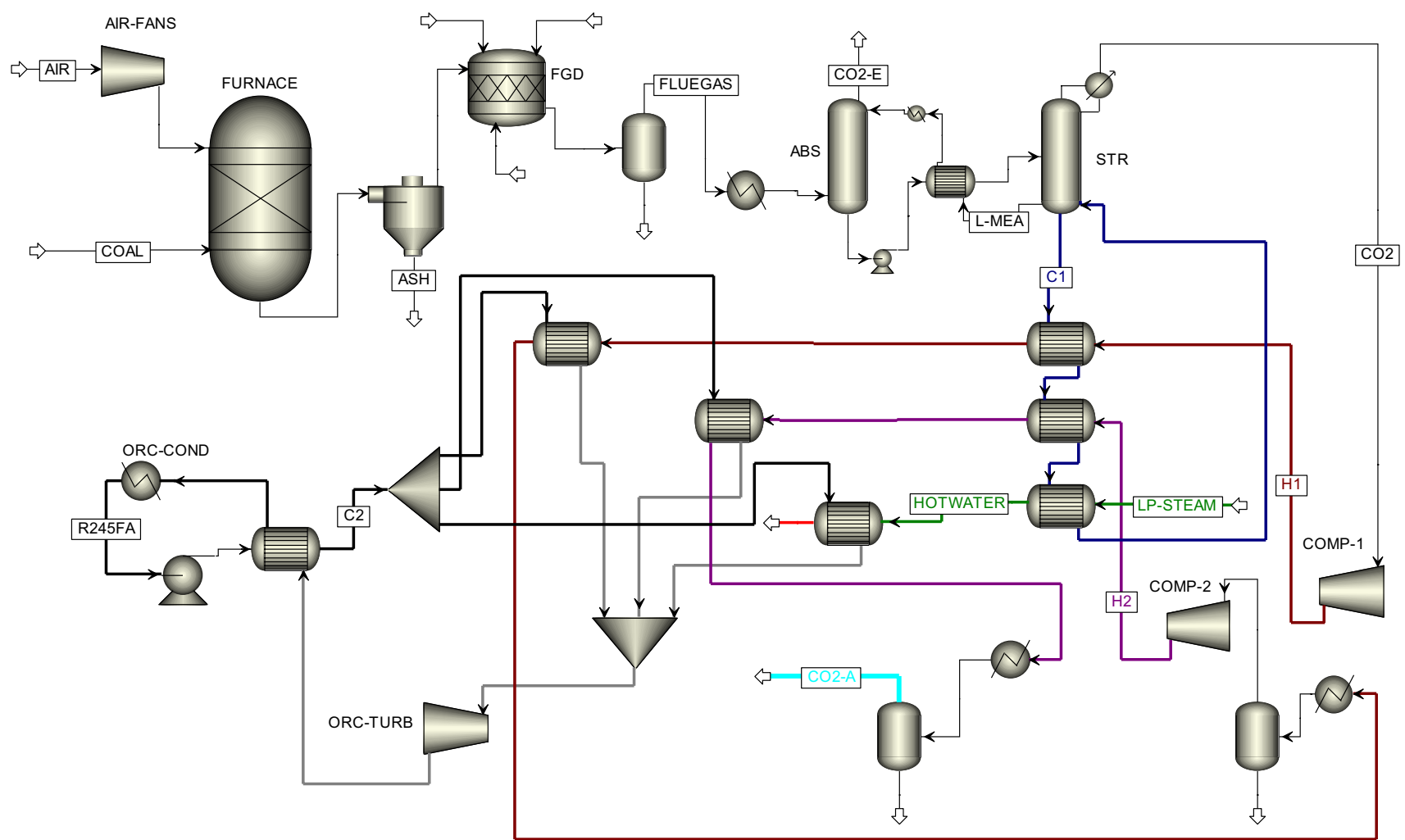

Fig. 10 Flowchart of SSWC configuration with thermal integration

integration that exhibited the best energetic result. The net power output increased as the amount of carbon captured decreased; decision makers can use this to observe the tradeoffs between the environmental impact and the power generation. The minimum GWP value obtained for the four CTCs was $123.12 \mathrm{eCO}_{2} \mathrm{~g} / \mathrm{kWh}$, which corresponded to the scenario of the SSWC configuration with a $90 \%$ level of capture and thermal integration.

With regard to the economic aspect, Table 6 presents the COE calculation results for each case studied. The CTC with the smallest COE in this study was C-4 (114.84 \$/MWh), and the COE exhibited an increase of 


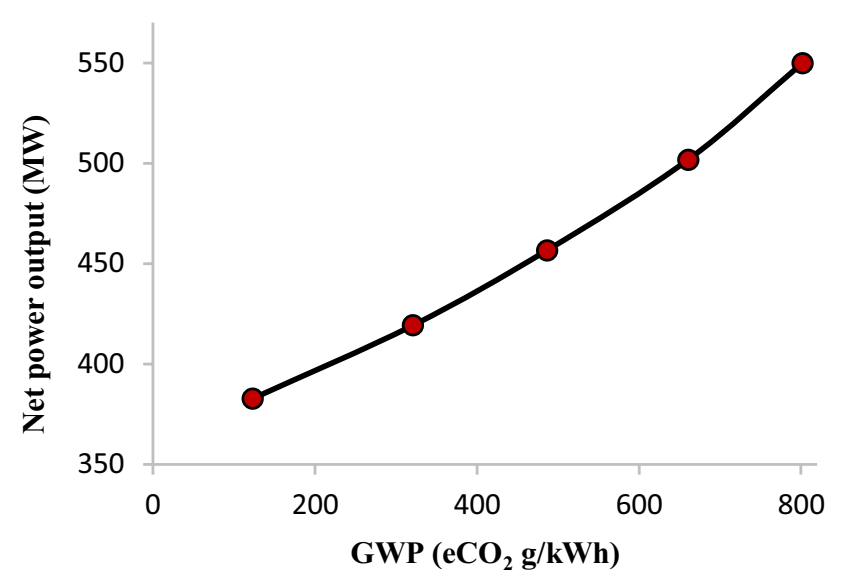

Fig. 11 Net power versus GWP for CTCs with various capture levels

95.05\%-97.09\% for each case, compared with that of the standalone plant. The economic, energetic, and environmental results differed among the cases. The results can help decision makers identify the best option based on the scenario that best suits their needs, which depends on different factors such as a country's regulations or environmental goals pertaining to the reduction of greenhouse gas emissions and the available economic resources, and then invest in the technologies required to meet those needs.

\section{Conclusions}

This study analyzed the coupling of a coal-fired power plant with monoethanolamine-based post-combustion carbon capture and organic Rankine cycles through thermal integration. The main results obtained were the global warming potential and net power output values for different compression-train configurations. The centrifugal compressor 8 configuration initially exhibited the best energetic results, with the smallest reduction in energy production (31.95\%) compared with the supersonic shockwave compressor configuration (33.58\%); this corresponded to a difference of $9 \mathrm{MW}_{\mathrm{e}}$ between the two configurations. The base case scenario had no thermal integration, and as the number of compression stages increased, the required amount of energy for the operation of the compression-train configuration decreased. Hence, there were differences in the net power output values of the coal-fired power plants with different compression-train configurations. Subsequently, with thermal integration, because the compression-train configurations with fewer compression stages attained higher temperature levels, they achieved better results in terms of the net power. The supersonic shockwave compressor configuration had the highest energy production because it had the lowest energy penalties as a result of the match between the hot streams of the compressors and the stripper reboiler stream. The difference in the net power results for the compression-train configurations with the highest power (supersonic shockwave compressors) and the compression-train configurations with the lowest power (centrifugal compressors 8) for scenarios with thermal integration was $4.6 \mathrm{MW}_{\mathrm{e}}$. The supersonic shockwave compressors exhibited a decrease of $29.83 \%$ in the global coal-fired power plant energy production. The analysis performed in this study indicated that thermal integration or a decrease in the capture level of each compression-train configuration could significantly reduce the energetic penalty as a result of the reduction in the amount of steam extracted using the energy generated by the organic Rankine cycle. Additionally, reducing the capture level affected the economic and design aspects of the compressors, absorption and stripping towers, and all the equipment required for the organic Rankine cycle, as well as for the capture process.

Table 6 Economic results

\begin{tabular}{llllll}
\hline Result & CFPP & CFPP+PCC+SSWC & CFPP+PCC+CC-4 & CFPP+PCC+CC-6 & CFPP+PCC+CC-8 \\
\hline TOC $(\$) \times 1000$ & $1,113,445$ & $1,522,778$ & $1,515,271$ & $1,519,078$ & $1,529,272$ \\
Total operating cost (\$/year) & $53,267,785$ & $81,295,885$ & $81,453,485$ & $81,121,885$ & $80,535,485$ \\
Fuel cost (\$/year) & $58,217,892$ & $58,217,892$ & $58,217,892$ & $58,217,892$ & $58,217,892$ \\
COE (\$MWh) & 58.9 & 115.08 & 114.89 & 115.46 & 116.09 \\
\hline
\end{tabular}


Acknowledgements The authors acknowledge the financial support provided by CONACYT and the Scientific Research Council (CIC_ UMSNH) for the development of this project, as well as the support from the faculty of Chemical Engineering at the Universidad Michoacana de San Nicolás de Hidalgo.

Authors' contributions Gerardo Esquivel-Patiño was involved in methodology, writing — original draft, and software. Fabricio NápolesRivera was involved in conceptualization, resources, funding acquisition, and writing - review and editing.

Funding The authors acknowledge the financial support of CONACYT and CIC_UMSNH.

\section{Declarations}

Conflict of interest The authors declare they have no conflicts of interest that might influence the work reported in this paper.

\section{References}

Araujo O, De Medeiros JL (2017) Carbon capture and storage technologies: present scenario and drivers of innovation. Curr Opin Chem Eng 17:22-34. https://doi.org/10.1016/j.coche.2017.05.004

Boucif N, Favre E, Roizard D (2008) $\mathrm{CO}_{2}$ capture in HFMM contactor with typical amine solutions: a numerical analysis. Chem Eng Sci 63(22):5375-5385. https://doi.org/10.1016/j.ces.2008.07.015

Choi WJ, Seo JB, Jang SY, Jung JH, Oh KJ (2009) Removal characteristics of $\mathrm{CO}_{2}$ using aqueous MEA/AMP solutions in the absorption and regeneration process. J Environ Sci 21:907-913. https:// doi.org/10.1016/S1001-0742(08)62360-8

Cormos A, Dinca C, Cormos C (2018) Energy efficiency improvements of post-combustion $\mathrm{CO}_{2}$ capture based on reactive gasliquid absorption applied for super-critical circulating fluidized bed combustion (CFBC) power plants. Clean Technol Environ Policy 20:1311-1321. https://doi.org/10.1007/s10098-018-1560-0

Desideri U, Antonelli M (2014) A simplified method for the evaluation of the performance of coal-fired power plant with carbon capture. Appl Therm Eng 64:263-272. https://doi.org/10.1016/j. applthermaleng.2013.12.012

DOE/NETL (2013) Cost and performance baseline for fossil energy plants volume 1: bituminous coal and natural gas to electricity, revision 2a. U.S. Department of Energy, National Energy Technology Laboratory

El-Hadri N, Viet-Quang D, Goetheer ELV, Abu-Zahra MRM (2017) Aqueous amine solution characterization for post-combustion $\mathrm{CO}_{2}$ capture process. Appl Energy 185:1433-1449. https://doi. org/10.1016/j.apenergy.2016.03.043

Ecoinvent (2019) https://www.ecoinvent.org/. Accessed 4 Oct 2019

Farahipour R, Karunanithi AT (2014) Life cycle environmental implications of $\mathrm{CO}_{2}$ capture and sequestration with ionic liquid 1-butyl-3-methylimidazolium acetate. ACS Sustain Chem Eng 2(11):2495-2500. https://doi.org/10.1021/sc400274b

Farajollahi H, Hossainpour S (2017) Application of organic Rankine cycle in integration of thermal power plant with post-combustion $\mathrm{CO}_{2}$ capture and compression. Energy 118:927-936. https://doi. org/10.1016/j.energy.2016.10.124

Filiz-Ozdil-Tumen N, Ridvan-Segmen M (2016) Investigation of the effect of the wáter phase in the evaporator inlet on economic performance for an Organic Rankine Cycle (ORC) based on industrial data. Appl Therm Eng 100:1042-1051. https://doi.org/10.1016/j. applthermaleng.2016.02.117

Flowers BS, Mittenthal MS, Jenkins AH et al (2017) 1,2,3-Trimethoxypropane: a glycerol-derived physical solvent for $\mathrm{CO}_{2}$ absorption. ACS Sustain Chem Eng 5(1):911-921. https://doi.org/10.1021/ acssuschemeng.6b02231

Gallagher KS, Bhandary R, Narassimhan E, Nguyen QT (2021) Banking on coal? Drivers of demand for Chinese overseas investments in coal in Bangladesh, India, Indonesia and Vietnam. Energy Res Soc Sci 71:101827. https://doi.org/10.1016/j.erss.2020.101827

Ghosh UK, Kentish SE, Stevens GW (2009) Absorption of carbon dioxide into aqueous potassium carbonate promoted by boric acid. Energy Procedia 1:1075-1081. https://doi.org/10.1016/j. egypro.2009.01.142

Gingerich DB, Mauter MS (2018) Retrofitting the regulated power plant: optimizing energy allocation to electricity generation, water treatment, and carbon capture processes at coal-fired generating facilities. ACS Sustain Chem Eng 6(2):2694-2703. https://doi. org/10.1021/acssuschemeng.7b04316

Gong X, Wang Y, Kuang T (2017) ZIF-8-based membranes for carbon dioxide capture and separation. ACS Sustain Chem Eng 5(12):11204-11214. https://doi.org/10.1021/acssuschem eng.7b03613

Gonzalez-Bravo R, Elsayed AE, Ponce-Ortega JM, Napoles-Rivera F, El-Halwagi MM (2015) Optimal design of thermal membrane distillation systems with heat integration with process plants. Appl Therm Eng 75:154-166. https://doi.org/10.1016/j.appltherma leng.2014.09.009

Goto K, Yogo K, Higashii T (2013) A review of efficiency penalty in a coal-fired power plant with post-combustion $\mathrm{CO}_{2}$ capture. Appl Energy 111:710-720. https://doi.org/10.1016/j.apene rgy.2013.05.020

Global CCS Institute (2020) Global status of CCS report. https://www. globalccsinstitute.com/resources/global-status-report/

Hanak DP, Biliyok C, Yeung H, Białecki R (2014) Heat integration and exergy analysis for a supercritical high-ash coal-fired power plant integrated with a post-combustion carbon capture process. Fuel 134:126-139. https://doi.org/10.1016/j.fuel.2014.05.036

Hanak DP, Kolios AJ, Biliyok C, Manovic V (2015) Probabilistic performance assessment of a coal-fired power plant. Appl Energy 139:350-364. https://doi.org/10.1016/j.apenergy.2014.10.079

IEA (2020a) Coal-fired power. IEA, Paris. https://www.iea.org/repor ts/coal-fired-power

IEA (2020b) Energy technology perspectives 2020. IEA, Paris. https:// www.iea.org/reports/energy-technology-perspectives-2020

IEA (2021) A rebound in global coal demand in 2021 is set to be shortlived, but no immediate decline in sight. IEA, Paris. https://www. iea.org/news/a-rebound-in-global-coal-demand-in-2021-is-set-tobe-short-lived-but-no-immediate-decline-in-sight

IPCC (2018) Changes in atmospheric constituents and in radiative forcing. https://www.ipcc.ch/publications_and_data/ar4/wg1/en/ch2s2 -10-2.html. Accessed 17 Oct 2019

IPCC (2019) Calentamiento global de $1,5^{\circ} \mathrm{C}$. https://www.ipcc. ch/site/assets/uploads/sites/2/2019/09/IPCC-Special-Repor t-1.5-SPM_es.pdf

Khalilpour R, Abbas A (2011) HEN optimization for efficient retrofitting of coal-fired power plants with post-combustion carbon capture. Int J Greenh Gas Control 5(2):189-199. https://doi. org/10.1016/j.ijggc.2010.10.006

Li H, Zhang Y, Yang Y, Han W, Yao M, Bai W, Zhang L (2019) Preliminary design assessment of supercritical $\mathrm{CO}_{2}$ cycle for commercial scale coal-fired power plants. Appl Therm Eng 158:113785. https ://doi.org/10.1016/j.applthermaleng.2019.113785

Linnenberg S, Darde V, Oexmann J, Kather A, van Well WJM, Thomsen K (2012) Evaluating the impact of an ammonia-based 
post-combustion $\mathrm{CO}_{2}$, capture process on a steam power plant with different cooling water temperatures. Int J Greenh Gas Control 10(463):1-14. https://doi.org/10.1016/j.ijggc.2012.05.003

Luo X, Wang M, Chen J (2015) Heat integration of natural gas combined cycle power plant integrated with post-combustion $\mathrm{CO}_{2}$ capture and compression. Fuel 151:110-117. https://doi. org/10.1016/j.fuel.2015.01.030

Nuchitprasittichai A, Cremaschi S (2013) Optimization of $\mathrm{CO}_{2}$ capture process with aqueous amines-a comparison of two simulationoptimization approaches. Ind Eng Chem Res 52(30):1023610243. https://doi.org/10.1021/ie3029366

Oh S-Y, Yun S, Kim J-K (2018) Process integration and design for maximizing energy efficiency of a coal-fired power plant integrated with amine-based $\mathrm{CO}_{2}$ capture process. Appl Energy 216:311-322. https://doi.org/10.1016/j.apenergy.2018.02.100

Ouyang T, Xu J, Su Z, Zhao Z, Huang G, Mo C (2021) A novel design of low-grade waste heat utilization for coal-fired power plants with sulfuric acid recovery. Energy Convers Manag 227:113640. https ://doi.org/10.1016/j.enconman.2020.113640

Pacala SW, Socolow R (2004) Stabilization wedges: solving the climate problem for the next 50 years with current technologies. Science 305(5686):968-972. https://doi.org/10.1126/science.1100103

Parvareh F, Sharma M, Qadir A, Milani D, Khalilpour R, Chiesa M, Abbas A (2014) Integration of solar energy in coal-fired power plants retrofitted with carbon capture: a review. Renew Sustain Energy Rev 38:1029-1044

Sanchez del Rio M, Gibbins J, Lucquiaud M (2017) On the retrofitting and repowering of coal power plants with post-combustion carbon capture: an advanced integration option with a gas turbine windbox. Int J Greenh Gas Control 58:299-311. https://doi. org/10.1016/j.ijggc.2016.09.015

Sarat-Chandra T, Maneesh-Kumar M, Mukherji S, Chauhan VS, Sarada R, Mudliar SN (2018) Comparative life cycle assessment of microalgae-mediated $\mathrm{CO}_{2}$ capture in open raceway pond and airlift photobioreactor system. Clean Technol Environ Policy 20:2357-2364. https://doi.org/10.1007/s10098-018-1612-5

Suleiman B, Abdulkareem AS, Abdulsalam YO, Musa U, Kovo AS, Mohammed IA (2016) Thermo-economic analysis of natural gas treatment process using triethanolamine (TEA) and diethanolamine (DEA) as gas sweeteners. J Nat Gas Sci Eng 36:184-201. https://doi.org/10.1016/j.jngse.2016.10.023

Tchanche BF, Lambrinos G, Frangoudakis A, Papadakis G (2011) Low-grade heat conversion into power using organic Rankine cycles: a review of various applications. Renew Sustain Energy Rev 15(8):3963-3979. https://doi.org/10.1016/j.rser.2011.07.024
Wang D, Li H, Wang C, Zhou C, Li X, Yang M (2021) Thermodynamic analysis of coal-fired power plant based on the feedwater heater drainage-air preheating system. Appl Therm Eng 185:116420. https://doi.org/10.1016/j.applthermaleng.2020.116420

Wang M, Lawal A, Stephenson P, Sidders J, Ramshaw C (2011) Postcombustion $\mathrm{CO}_{2}$ capture with chemical absorption: a state-ofthe-art review. Chem Eng Res Des 89:1609-1624. https://doi. org/10.1016/j.cherd.2010.11.005

Wang Y, Chao Z, Jakobsen HA (2011) Numerical study of hydrogen production by the sorption-enhanced steam methane reforming process with online $\mathrm{CO}_{2}$ capture as operated in fluidized bed reactors. Clean Technol Environ Policy 13:559-565. https://doi. org/10.1007/s10098-011-0368-y

Witkowski AS, Majkut M (2012) The impact of $\mathrm{CO}_{2}$ compression systems on the compressor power required for a pulverized coal-fired power plant in post-combustion carbon dioxide sequestration. Arch Mech Eng 59(3):343-360. https://doi.org/10.2478/v1018 0-012-0018-x

Xiong J, Zhao H, Zheng C (2011) Exergy analysis of a $600 \mathrm{MWe}$ oxy-combustion pulverized-coal-fired power plant. Energy Fuels 35:3854-3864. https://doi.org/10.1021/ef200702k

Yee TF, Grossmann IE (1990) Simultaneous optimization models for heat integration-II. Heat exchanger network synthesis. Comput Chem Eng 14(10):1165-1185. https://doi.org/10.1016/00981354(90)85010-8

Zhai R, Qi J, Zhu Y, Zhao M, Yang Y (2017) Novel system integrations of $1000 \mathrm{MW}$ coal-fired power plant retrofitted with solar energy and $\mathrm{CO}_{2}$ capture system. Appl Therm Eng 125:1133-1145. https ://doi.org/10.1016/j.applthermaleng.2017.07.093

Zhang W, Jin X, Tu W, Ma Q, Mao M, Cui C (2017) Development of MEA-based $\mathrm{CO}_{2}$ phase change absorbent. Appl Energy 195:316323. https://doi.org/10.1016/j.apenergy.2017.03.050

Zhang X, Zhang CF, Liu Y (2002) Kinetics of absorption of $\mathrm{CO}_{2}$ into aqueous solution of MDEA blended with DEA. Ind Eng Chem Res 41:1135-1141. https://doi.org/10.1021/ie010605j

Zhang Y, Chen H, Chen C-C, Plaza JM, Dugas R, Rochelle GT (2009) Rate-based process modeling study of $\mathrm{CO}_{2}$ capture with aqueous monoethanolamine solution. Ind Eng Chem Res 48(20):92339246. https://doi.org/10.1021/ie900068k

Publisher's Note Springer Nature remains neutral with regard to jurisdictional claims in published maps and institutional affiliations. 